\title{
Accountability Mechanisms in Community-Driven Reconstruction in Eastern Democratic Republic of Congo
}

\author{
${ }^{* * * *}$ Patrick Milabyo Kyamusugulwa ${ }^{1},{ }^{*}$ Dorothea Hilhorst and ${ }^{* * *}$ Carolien Jacobs \\ *Erasmus University of Rotterdam International Institute of Social Studies, The Netherlands; ${ }^{* *}$ Institut \\ Supérieur des Techniques Médicales de Bukavu, The Democratic Republic of Congo; ${ }^{* * *}$ Leiden University, \\ Van Vollenhoven Institute for Law, Governance and Development, The Netherlands. \\ Email of the corresponding author: pmilabyo@gmail.com
}

\begin{abstract}
A lack of accountability is often considered a root cause of conflict. Many post-conflict reconstruction efforts therefore aim to enhance accountability between authorities and the population through community-driven reconstruction (CDR) programmes. This article examines the details of the accountability mechanisms in the Tushiriki CDR programme in eastern Democratic Republic of Congo. Based on ethnographic research, we found little impact of formal programme accountability. Rather, accountability was shaped differently and had its own context-specific meaning. To make accountability more sustainable, stronger embeddedness in local institutions and more appropriate translations of abstract concepts into the local context are needed.
\end{abstract}

Key words: accountability, community-driven reconstruction, Democratic Republic of Congo.

\footnotetext{
${ }^{1}$ Acknowledgments: We thank the International Rescue Committee/Stichting Vluchteling for funding provided to author Patrick Milabyo Kyamusugulwa, and DFID for funding as part of the Secure Livelihoods Research Consortium to authors Dorothea Hilhorst and Carolien Jacobs. Patrick Milabyo Kyamusugulwa is grateful to the Marie-Curie Fellowship for its support during the inception phase of this research and to DFID during the revision phase of the paper. Special thanks go to communities of Burhinyi, Luhwindja and Kaziba for taking part in this research. Finally, we are thankful to two anonymous referees for their advice and critiques.
} 


\section{Introduction}

Post-war reconstruction interventions increasingly espouse a commitment to being bottom-up and contextual, looking beyond state institutions and providing space for local ownership (Hilhorst et al. 2010; Kyamusugulwa 2013). One manifestation of this trend is the expansion of communitydriven development programmes in areas of recovery after conflict. In these areas, such interventions are called community-driven reconstruction (CDR) programmes. CDR is promoted by the World Bank and other international agencies. One major proponent is the International Rescue Committee (IRC), which has implemented large UK-Aid-supported CDR programmes in contexts including post-conflict Liberia, Sierra Leone and the Democratic Republic of Congo (DRC) (Fearon et al. 2009; Humphreys et al. 2012). Numerous other international nongovernmental organisations (NGOs) have developed participatory programmes for communitybased reconstruction that follow similar working methods, although not always under the label of CDR.

Typically, these bottom-up reconstruction programmes combine 'hardware' reconstruction objectives such as the restoration of schools, roads and services with 'software' objectives of enhancing democratic values and the local-level accountability of authorities. As one of the policy papers about CDR states, this is important in post-conflict contexts, where levels of trust, accountability and social cohesion are relatively low (Cliffe, et al. 2003). A study on CDR likewise observes that these programmes are based on the idea that people's involvement in decisionmaking and accountability processes may lead to change from conflict to development by addressing root causes of conflict, such as corruption, a lack of accountability, the absence of trust between people and institutions, and weakly functioning institutions (Maynard and Jodi 2007). 
However, some recent robust evaluations, based on large-scale randomised controlled trials, have brought out sobering messages about these software objectives. Studies in the DRC and Sierra Leone reported no significant differences between the 'treatment' areas (part of the CDR effort) and the non-treatment areas (Humphreys et al. 2012). Findings in Liberia showed that social cohesion can increase through post-conflict development aid, but the mechanisms behind this change remain largely unclear. Overall, the impact of community-driven development on social cohesion seems limited (Fearon et al. 2009).

The lack of effectiveness established by these evaluations may be conclusive, but the question of how these findings can be explained remains. Previous work has pointed out that the effectiveness of CDR is influenced by many different dynamics, such as local power relations, labour availability or accountability mechanisms (Kyamusugulwa and Hilhorst 2015). This paper aims to contribute to answering the question by focusing on CDR policies' claim that building social accountability mechanisms into CDR programmes will enhance the transition from conflict to development. We examine accountability practices in a CDR programme in eastern DRC. In presenting our findings, we focus on three mechanisms: general assemblies, the display of reports and civil society as a watchdog. We also analyse how accountability works in practice and how the prescribed mechanisms contribute to this.

In addition to following these specific mechanisms, we also explore how accountability emerged in unplanned ways around the programme through the development of community social practices allowing people to hold authorities accountable for their actions. These practices of what may be called moral or everyday accountability (Hilhorst 2003, pp 125-146) are integrated into everyday life and concern all kinds of ways that people convince their leaders to live up what they consider their responsibilities. Relevant behaviours here range from pleading or flattery to coercion 
or even violence. One of the questions raised in this article is how such everyday forms of accountability permeate the formal accountability mechanisms introduced by CDR.

Our interest in the accountability mechanisms of CDR begins with the simple premise that, regardless of the development intentions inspiring these programmes and the resources devoted to them, their effect crucially depends on the mechanisms used to achieve their objectives. Thus, this study asked how the theme of accountability was translated into specific mechanisms during the project implementation, and how these mechanisms worked in practice.

The article is part of an 'aidnography' (ethnography of aid) of the Tushiriki Programme of IRC by the first author in three chiefdoms of the DRC. His study concerned a PhD project with intensive fieldwork from 2008 to 2010. The second and third author supervised the study and joined the fieldwork for brief periods of time.

The paper is structured as follows: We begin by highlighting the background of accountability in development aid, with a particular focus on the DRC. We then describe the setting of the Tushiriki Programme, as well as the methods used in this study. Next, we present and analyse three accountability mechanisms used in the programme. In the final section, we conclude the article and outline the main implications of the research.

\section{Background of accountability in development aid}

Enhancing accountability is a major objective of CDR. Rather than aiming for accountability through institutions such as elections, social accountability is sought in everyday relations between authorities and the population. Transparency is part of accountability and obliges powerholders to provide information and to explain their actions. Social accountability goes beyond transparency, 
as it also refers to responsibilities. Authorities must take responsibility and can be held responsible. In an accountable situation, a constituency has the capacity of enforcement and may impose sanctions on powerholders who violate their public duties (Ackerman 2004). Increasingly, people are expected to be active participants rather than merely passive beneficiaries of aid, and accountability is a precondition for genuine participation (Rubenstein 2007). The promotion of social accountability in development programming is closely related to participatory development, but an important difference is that the focus on social accountability has a strong emphasis on bringing about changes in relations with local authorities, rather than being focused on the implementation of the project.

The literature suggests three reasons why enhancing social accountability contributes to improving governance and deepening democracy (Malena et al. 2004). First, accountability provides a way of discouraging and penalising corruption by strengthening the demand side of governance (McLean et al. 2005). Second, accountability can be used as a goal in itself or as a means of improving project effectiveness, efficiency and economy (Cavill and Sohail 2007). Third, it is claimed that local government and other local institutions will become more effective and more responsive to citizens' desires if popular participation and accountability are built into local governance (Blair 2000).

Previous work on social accountability distinguishes between formal and informal accountability. Formal — or rational—accountability constitutes reporting mechanisms to make performance transparent and controllable. Informal—or moral—accountability is geared towards creating trust and commonality through everyday practice. CDR interventions aim to introduce more formal accountability into the interactions between the population participating in humanitarian or development agencies' programmes and the local authorities. One way to achieve 
this is through public meetings. Bringing information and findings into the public sphere and generating public debate around them are considered key elements for accountability. Another accountability mechanism involves enhancing countervailing powers by encouraging civil society to hold authorities answerable on public affairs: the watchdog role (Malena et al. 2004).

The promotion of local accountability as part of a development programme may increase knowledge and transparency and create conditions fostering empowerment, efficiency, assurance and honesty (Rubenstein 2007). However, it also risks creating conflicts between local powerholders and the newly empowered, a waste of resources, turning attention away from other important issues, the enhancement of mistrust and difficulties managing multiple accountabilities (Rubenstein 2007).

\section{A brief history of accountability in the DRC}

The accountability context of the DRC is complex, given the prolonged conflict that affected the eastern part of the country especially from 1996 to 2003. Pockets of violence continue to exist, particularly in the Kivu Provinces. However, for large parts of the provinces, conflict is no longer an everyday reality, and there is room for programmes like Tushiriki to work towards Communitydriven reconstruction.

To understand the complexity of society in the DRC today-and to be able to tailor interventions — one also needs to consider the pre-conflict period (i.e. the Mobutu era, 1965-1997). Mobutu came to power through a coup d'état. Under his regime of Zairianisation, people were encouraged to fend for themselves, along the adage of the imaginary Article 15 of the Congolese Constitution: Débrouillez-vous. Patronage, corruption, maladministration and fraud were institutionalised; soldiers were allowed to prey upon the population, the state bureaucracy was 
encouraged to be unaccountable and the president saw little difference between the nation's resources and his own personal wealth. The state apparatus was encouraged to be self-financing through the exploitation of its own people, without any sense of a social contract-like responsibility. It is in this context that the wars of 1996-1997 and 1998-2003 occurred (Reyntjens 2007; Trefon 2011). In 1997 the Mobutu regime was overthrown by Laurent-Desiré Kabila, who was succeeded by his son in 2001. Congo's first democratic elections took place only in 2006. Throughout the Kabila regime, from 1997-2008, the situation in eastern DRC could be described as no war and no peace: some areas were controlled by armed groups, whereas other areas were under government control. Territories would frequently shift between forces. The international community balanced between humanitarian and development interventions. The Tushiriki programme was a reconstruction programme that aimed to restore small-scale infrastructure and at the same time introduce practice of accountability in local development and governance.

\section{Setting, programme description and methods}

\section{Setting and programme description}

This research was carried out in two of the three chiefdoms targeted by the Tushiriki Programme: Burhinyi and Luhwindja, located in Mwenga territory, South Kivu province, eastern DRC. Both chiefdoms were heavily affected by the conflict from 1996 to 2003, which made them obvious targets for CDR interventions. The third chiefdom, Kaziba, had started earlier with the programme and hence was past the stage that was interesting to observe for this research.

Within the chiefdoms of Burhinyi and Luhwindja, the IRC's programme targeted 44,173 people living in eight randomly selected communities. The total population of the chiefdoms was 103,066. Although the programme spoke of Tushiriki communities and villages, these were artificially 
designated by the programme (by selecting a part of a real administrative unit), in such a way that a 'Tushiriki community' consisted of nearly 6,000 inhabitants, and a 'Tushiriki village' was inhabited by about 1,200 residents. Our research has focused on the level of villages, and the remainder to the article only deals with that level of the programme.

The CDR programme was called Tushiriki, meaning 'let us all be involved in it together'. It was implemented by the American-based IRC through its office in Bukavu in South Kivu. The IRC has been operating in South Kivu since 1996. The Tushiriki Programme is one of two CDR programmes implemented by the IRC from 2008 to 2010. The other programme was the larger and longer lasting programme of Tuungane (Humphreys et al. 2012). Tushiriki was funded by the Dutch NGO Stichting Vluchteling (SV).

The Tushiriki programme aimed to strengthen the capacity of civil society by increasing the understanding of good governance principles and practices and to promote advocacy efforts towards policymakers on behalf of communities. To achieve these aims, the programme focused on both civil society and community development. For community development, village development committees (VDCs) were set up to design and plan the 'hardware' of the reconstruction projects, such as classrooms, schoolmasters' offices and local roads. On the 'software' side, to familiarise beneficiaries with accountability, they were involved in committee elections; project identification, management and execution; training and regular general reporting assemblies (GRA) (Kyamusugulwa et al. 2014).

The 10 members of the VDCs were elected during meetings. Equal participation of men and women was required. Each of the 34 target villages in the two studied chiefdoms was allocated a block grant of 3,000 USD. The villages were able to make decisions about the allocation of these 
funds within the programme's parameters. These parameters meant that they had to appoint a committee and were required to learn about governance principles through the implementation of the project. Projects could consist of the construction of a school, a road or a schoolmaster's office. Working parallel to the VDCs, each Tushiriki village had its own civil society component: Local NGOs were selected to be in charge of supporting the activities of partnering NGOs and community-based organisations (CBO) through training on local governance and advocacy. In addition, the VDCs were checked by a control commission of two people: the Relais de Qualité, who acted as the eyes of the population. These were a man and a woman that were elected by the programme participants. They were supposed to denounce any mismanagement within the programme. For this they received training from the IRC or its NGO partners.

\section{Methods}

The data for the present study were drawn from in-depth qualitative fieldwork conducted by the first author from 2008 to 2010 during the Tushiriki Programme. This included 36 focus groups of residents and 50 individual interviews, as well as observations of general assemblies, training sessions, reconstruction activities and elections. The first author also conducted follow-up visits in the area in 2013 and 2015. The research participants, who were consulted in formal and informal settings, included committee members, elected team members and members of CBOs. Some people were interviewed several times. At the chiefdom level, interviews were also conducted with the local administrator based in Luhwindja. He also interviewed nine staff members of the Tushiriki Programme working in the study area.

The programme elements outlined in this article were followed in 29 of the 49 target villages in the Tushiriki Programme. Villages were selected in such a way that multiple villages could be visited during one period of fieldwork. The villages were visited 5 to 7 times (usually for one day) 
in the period before, during and after project implementation. After an initial analysis of the full set of data from the 29 villages, three cases have been selected to presentation in this paper. The case studies reveal how these accountability mechanisms worked in practice as applied in the Tushiriki Programme. The cases represent similar processes found in the other areas, and the analysis partly draws on the data set of all villages.

\section{Results: three case studies}

\section{A general reporting assembly}

Public meetings are a powerful component of accountability initiatives. Malena et al. (2004) have recognised that bringing information and findings into the public sphere and generating public debate around them is key for most accountability initiatives. Additionally, Cliffe et al. (2003) identify open meetings as a common way of encouraging accountability.

The meetings in the Tushiriki programme were for example meant to elect committee members. The method of election was as follows. During the meeting, the Tushiriki staff would explain what was expected from committee members and ask who would like to be considered for the position. The people who raised their hands were asked to step outside and leave the meeting area. Then the staff would call out the names one by one and ask people to raise their hand if it was their favourite candidate. Even though the process was open and transparent, it was observed at several occasions how prospective members would discuss their candidacy beforehand with the chief or priest of the village. These village leaders were then seen to promote particular candidates, usually relatives or other people that were close to them. These dynamics surrounding the meeting were important in pre-selecting candidates and in the end committees consisted mainly of people who were not likely going to call their leaders to account. 
One of the problems that was often encountered is that the meetings did not reach their quorum. In practice, this was often resolved by combining meetings with church gatherings, as happened in a public meeting in Karwera, a Tushiriki village in the Burhinyi chiefdom. Karwera is led by a chief and has one local church, the Cinquième Communauté des Eglises Libres de Pentecôte en Afrique ( $5^{\text {th }}$ CELPA). The social standing of these two bodies strongly influences people's behaviour. In 2008, the village had an estimated population of 953 . This location is accessible by car. In the past, a number of self-initiated associations were set up to organise people into groups for carrying out agricultural work and bee-keeping. To join these groups, people had to pay 5 USD. As one resident noted, these associations did not have a long-term outlook and were not very serious regarding the services that they were supposed to provide to their members. As a result, the associations lost popularity, and membership numbers declined.

Before the Tushiriki Programme came to the village in 2008, people had already obtained experience with the functioning of an international programme through the reconstruction of the Budaha primary school by the Associazione Volontari per il Servizio Internazionale (AVSI), a UNICEF-funded project. For that project, the residents of two villages contributed labour and local materials, carrying water, stones and sand from the river. One reason why AVSI selected this school was the area's accessibility by road, making it easy for the implementing agency to visit the school. Residents therefore realised the importance of good infrastructure. Hence, when these people could select their own village project as part of the Tushiriki Programme, they decided to target the local road for reconstruction. This idea was initiated by local leaders, including the chief of the community, and then became popular among the residents. As one of the residents put it, 'a road facilitates commercial activities, access to health services and schooling'. 
After the first and second disbursements of Tushiriki funds to the Karwera VDC, a GRA was required to update the residents about the project. Only then would the additional funds be released. Several efforts had been made to organise a GRA, but the committee never managed to mobilise the required minimum of at least $40 \%$ of the residents for this special public meeting. Eventually, it was decided to hold the GRA at a Sunday church service. Committee members and church leaders were closely linked, and, therefore, the GRA was able to get a prominent place during the service. Tushiriki field staff also participated. In total, around 200 people attended, including children, but the $40 \%$ attendance requirement remained unmet. The male VDC president, a welleducated development technician, informed the attendees that the Tushiriki had released two tranches of money summing to 1,315 USD of the total promised 3,000 USD. He further informed them that this money had been spent on travelling to the provincial capital to buy materials for the road rehabilitation, such as trowels, forks and wheelbarrows, and on wages for road workers, who were selected from among the Karwera residents.

After the report was given, three questions were raised, all by men. The questions concerned the wages of the VDC members, about reconstructing the church building and about the next step at the CDC level for the project. The president quickly answered those questions, noting that the VDC members were not paid, because otherwise the realisation of upgrading the road could hardly be achieved, that nothing was planned for the church reconstruction and that there would be an election for the project at the CDC. His responses evoked no discussion, but the first author overheard some youth whispering that some costs were too high. After this special announcement, the pastor ended the service with a final prayer.

This case epitomises how difficult it was to have a real discussion of the project's progress in a public meeting. The population was not accustomed to this type of accountability in development 
projects. The AVSI/UNICEF project, for instance, did not require any reporting to the population, and hence there was no such expectation on the basis of previous experiences. Interviewed people just appreciated the school building, with its solid walls of burnt bricks, roofs, floors, blackboards and six classrooms equipped with tables. In contrast, the Tushiriki Programme did have the obligation of a GRA, but it turned out to be difficult to interest people in attending these meetings. Usually, the first meetings were well-attended, but once it was clear that attendance did not provide concrete benefits, the attendant numbers dropped.

When the quorum was not reached, it was smart to embed the meeting in an existing social institution with relatively high participation: the church service. However, this would further diminish the likelihood of an open discussion. People were not used to having open discussions in the church setting, particularly discussions about money matters. In addition, people were inclined to follow the opinion of the organising leaders - in this case the church leaders. Hence, the GRA mainly served as an obligatory hurdle without much critical reflection.

Previous research has maintained that public meetings may have an effect in community driven programmes. The large CDR evaluation on Tuungane in Eastern DRC found, for instance, that people often used community meetings to voice their opinion (Humphreys 2008). While the mechanism of public meetings thus has its merits, local residents may have different ideas about this. In the case of the Tushiriki Programme, people quickly lost interest in meetings that failed to produce tangible results. This was resolved in the case described above by embedding the public meeting in already existing church services, even though this limited the discussion. The Tushiriki Programme required separate meetings with a strict quorum, but this was adapted locally. In this case, the public meeting as an accountability mechanism was adapted locally and transformed into a question-and-answer session held during a church service. The prescribed meeting thus took 
place through the existing institution of the church. Prevailing social norms, however, hindered the open discussion of money matters.

\section{Displaying reports}

Apart from the GRAs, the Tushiriki protocol included a procedure for displaying reports providing updates about finances and project implementation. We observed this mechanism ourselves in three communities. The protocol states that the VDC should post a report about the project activities, including a financial report on the amounts received and spent (IRC and CARE 2009). For this case, we explain how the reports were received in three villages: Cibanda II and Mubone, located in the Luhwindja chiefdom, and Kanyimba village, located in the Burhinyi chiefdom.

In each of these project villages, reports of the expenditures made were displayed, as required by the programme. However, participants of the research indicated that, despite the public display of the reports, nobody was willing to read them. People were not used to reading this kind of information, and many of them, especially women, were illiterate. For instance, a report was attached to the door of the Mubone 5th CELPA church one day. When asked about this report, a group of masons who were constructing a school near the church said that they had not read it. Further, they were unaware of any expenditure report. Interestingly, one of the masons noted that they already knew what was happening in the project because they could talk easily to the VDC members about it.

Similarly, on March 25, 2009, when the first author visited Cibanda II village, a VDC report was displayed at a junction of two local roads. The report mentioned one decameter (an instrument used to measure the length of road that was completed per day), 40 trowels, 20 forks, 15 pickaxes, one piece of string and two machetes that had been purchased. Other materials were mentioned as 
still needed, especially two wheelbarrows, seven trowels and three forks. These materials were for the construction of a road connecting Cibanda II village with the seat of the chiefdom. Strikingly, the report did not mention the exact amount of money received or spent for these materials. There were also some places in the report where the exact number of materials bought was crossed out, as though they were uncertain. Before people were able to read the report, it was taken away by the young people of the village.

In Kanyimba village, the experience of displaying reports was similar to the stories from Mubone and Cibanda II. Here, a report providing details about the amount of money received by the VDC was pinned up on display. The male VDC secretary soon observed some children taking the report away, arguing that it was for a football match. In fact, youngsters in the village thought that every poster was a football advertisement, as this was the only activity that was ever advertised.

The above examples show that the display of reports did not contribute much to accountability. The reports lacked detailed information, and people did not read them, either because they were not interested, because they were illiterate or because the announcements were quickly removed. However, an alternative form of accountability became clear in the words of one of the masons. He considered it enough to talk about the project with a VDC member (in the street or during neighbourly visits) because he trusted the VDC members. In general, it was found that community members involved in the Tushiriki preferred everyday conversations about the projects over formal reports, especially written reports. Although it has been argued that displaying council decisions, budgets and expenditures on public notice boards is a way of encouraging accountability, people's perceptions of this may differ, especially in areas dominated by oral tradition (Cliffe et al. 2003). In the Tushiriki Programme, people could obtain information in more informal ways if they felt 
they needed this. In the small communities where the Tushiriki was implemented, neighbours often sit together at the end of the afternoon and in these visits topics concerning the project could be brought up in a natural way. The mason in the case described above, made it clear that he trusted the account of VDC members. As VDC members were often close to the community leaders, their words were often respected.

Throughout the fieldwork, the first author repeatedly noticed that participants in the projects most of whom were illiterate - were satisfied with observing concrete realisations of the project had little expectations regarding reports, and certainly not regarding written reports. Several interviewees remarked that it was considered inappropriate to provide financial information in a written report.

\section{Community-based organisations as watchdogs}

An important aspect of building accountability in CDR is strengthening countervailing powers of CBOs and encouraging them to hold authorities responsible. The Tushiriki Programme had defined a role for community-based organisations, such as parent-teacher or farmer associations, to act as a watchdog to ensure that the VDC was accountable to residents about the selected project. This aspect is exemplified by the case of Ishogwe village, in Luhwindja chiefdom. In 2008, this village had 1,577 registered inhabitants. The village has one primary school, which was founded and continues to be managed by the 5th CELPA church. There is no secondary school and no a health centre in the village. The Protestant church and the chieftaincy are the most prominent institutions. At the time of this research, the village was headed by an interim chief.

In 2008, when the Tushiriki Programme came to the village, a series of public meetings was held for VDC elections, needs identification, project selection and budget approval. Following this 
process, Ishogwe residents selected the reconstruction of a bridge as their project, although the available grant of 3,000 USD was insufficient to complete this project. Residents told the first author that they selected the bridge because it would connect three villages even during flooding. The previously existing bridge had collapsed over five years earlier, and the inhabitants felt the project was crucial for them and for the area.

Of the $70 \mathrm{CBOs}$ in the chiefdom, 36 were selected for involvement in the Tushiriki programme. These included several CBOs of Ishogwe, notably the parent-teacher association and a women's group. The CBOs were supposed to serve as watchdogs for the VDCs, which were managing the project funds on behalf of the population. The CBOs were trained by local NGOs that had been selected as partners of the Tushiriki programme. In Ishogwe, training was conducted by two NGOs, Centre d'Etudes de Documentation et d'Animation Civique (CEDAC), and Action pour le Développement en Milieux Ruraux (ADMR). The NGOs provided training for both the VDCs and the CBOs to familiarise them with the watchdog idea. Governance, bookkeeping and advocacy were among the topics developed by CEDAC and ADMR in the training session. However, neither of the NGOs had previous experience in exercising a watchdog role or in advocacy. CEDAC was well known for raising awareness regarding citizens' duties, whereas ADMR was best known for planting trees.

During the training, ADMR and CEDAC distributed basic stationery to every participating $\mathrm{CBO}$ for reporting their activities to the NGOs. One copy of the training module was given to the president of each VDC and CBO. Within the community setting, the CBOs were said to play the role of a check and balance on the VDC project management and to regularly monitor progressor the lack thereof - on the project. If the VDC proved to be less than accountable to its constituency, participants were told that they were entitled to ask questions of the VDC members. 
Additionally, if they noticed no progress, the $\mathrm{CBO}$ members were told to question the VDC members about this.

However, the aim of the training was not always reflected in what people reported learning. During follow-up interviews, we noted that most participants were not able to recall the message of the training in clear terms. One attendee, for example, remembered two things: (i) democracy and avoiding a dictatorship and (ii) working together to include disabled people. More generally, when recalling the training, interviewees who had participated in these training sessions reported that there were short training sessions with big groups of participants (up to 100) and that part of the training was in French. Some educated attendees spoke French, but, even for these people, the abstract concepts of the training were difficult to grasp. Concepts such as accountability, governance and advocacy were not translated into the local language or were translated in a limited way. Hence, in taking partners on board, Borren (2000) has emphasised the importance of defining beforehand how to engage with a partner, as well as the crucial role of empowerment and emancipatory learning. An important note is the simple observation that one cannot build capacities in others that he/she does not have him/herself (Eade 2007). Clearly, the failure in the technical assistance of CBOs by NGOs was one of the problems.

The checks and balances of the CBOs' watchdog role was generally complicated by the fact that people are often connected to each other in various ways in small communities. Members of the two committees and the control commission were residents of the same village and belonged to relatively close families or clans. For instance, the chief of the village was an adviser to the vicepresident of a CBO and also a member of the VDC. Raising criticism against the VDC then became difficult. When setting up interventions, complaints about preferential treatment were common 
from people who were not targeted. Ultimately, however, complaints would simmer out because both beneficiaries and decision takers had an interest in maintaining their mutual relationships.

In terms of accountability within the existing institutions, neither the chieftaincy nor the church had a history of transparency regarding the management of funds. However, on several occasions, we observed that both the chieftaincy and the church informed people about contributions to a project, either by shouting through a megaphone or during a church service. The Tushiriki Programme used the same means of informing people. What was new was the message of Tushiriki on the need for transparency about project funding, including disclosing details about expenditures and creating an arena for open discussion about the VDCs decisions. This was a sensitive issue, as the public discussion of financial matters goes against local culture. The accountability training provided did not overcome this. Additionally, not all participants had a good understanding of the training's message because of language barriers, insufficient tailoring to fit the local context and a failure to provide adequate tools for people to take up their watchdog role.

In short, the watchdog mechanism of accountability was hampered by a lack of capacity among the NGOs and CBOs involved, an inadequate translation of key concepts into the local vernacular and people's everyday realities, and the complexity of relations between the actors involved at the community level.

\section{Conclusions}

Community-driven reconstruction programmes aiming to enhance accountability has become popular in conflict-affected areas. This paper followed one such programme in Eastern DRC. Even though an important claim of community-driven reconstruction is to address root causes of conflict, a first conclusion is that none of the mechanisms that were introduced for social 
accountability were especially designed to address causes of the conflict, and nor were they evaluated in this light. The programme rested on the general assumption that governance principles such as accountability were connected to the root causes of conflict, such as a lack of trust and limited social cohesion. This raises the question to what extent community-driven reconstruction programmes address conflict or whether they use rhetoric of conflict in order to implement a set of actions that would probably be done in the same way in a peaceful area?

\section{[Please insert Figure 1 and Photo 1 here]}

This paper has analysed people's views about accountability and its three mechanisms as applied in the Tushiriki Programme (Cfr. Figure 1). We have shown that the implementation of the mechanisms did not have a major impact on the accountability within the programme. The first mechanism presented in this paper was the GRA. Organising a public meeting during a church service was helpful in achieving a relatively high turnout. However, this was not a setting where people would usually have discussions. In addition, according to local culture, financial matters should not be spoken about publicly (Cfr. Photo 1). Hence, the mechanism of public meetings to increase financial accountability does not seem adequate. The second mechanism discussed was the prescribed public display of reports within communities. This had limited impact because of high levels of illiteracy and people not noticing the posted reports. People were clearly more accustomed to absorbing information through everyday conversations than from reading written text. Additionally, sensitive financial issues were barely mentioned in the reports. People were mostly interested in tangible results and much less in how they had come about. Finally, we discussed the watchdog role of CBOs. We showed that CBOs often either lacked the capacity for this or were too closely connected to the VDCs to act as a genuine counterweight. The latter issue seems difficult to overcome in small communities. However, attempts were made to address the 
lack of capacity through training, but this had only limited results because of language barriers and the high number of participants.

The formal social accountability mechanisms operated by blending them in practice with informal mechanisms. In the cases we presented, we found that people knew about the projects through everyday conversations and meetings were better attended when they were combined with church services. Does this mean that accountability came nonetheless about?

Social accountability, as discussed in the background of this paper, concerns transparency of powerholders to explain their actions. Going beyond transparency alone, social accountability also implies that authorities can be held responsible for their actions.

In the local adaptations of accountability that we observed in the Tushiriki villages, transparency did take shape, and community members were well informed about what happened with the projects in everyday conversations or meetings. The other side of holding authorities to account, did not come about. An important reason for this was that the dynamics around the selection of VDC members tended to be result in a VDC, as well as designated watchdogs, that were close to the village leaders (chiefs or pastors) and not likely to take a critical stance to the authorities. Holding meetings in the church would gather many people, but deterred the openness of the conversation, as church goers are used to listen rather than to speak during the services. Finally, it was found that common people in the villages tended to show respect to the VDC members and would take their word about the projects rather than probing deeper with questions on their governance.

We can thus conclude that accountability came about in the Tushiriki programme, but was translated into informal and oral rather than formal and written mechanisms. While transparency 
was therefore rather high, accountability was shaped in the process by local power realities, which are associated with churches and chieftaincy institutions.

For the successful implementation of accountability mechanisms, it has been suggested that agencies must embed these mechanisms in the local context and take into account the values and norms associated with traditional forms of collective action (Pellini and Ayres 2007). Our findings bring out that such an adaptation to the local context enhances the working of accountability, yet restricts its possible impact as it becomes part of local power dynamics in the process.

We argue that, to create a sustainable culture of accountability, there is indeed a need for a more appropriate translation of abstract concepts such as accountability into the local context. There is also a need to better understand the adjustments that take place when formal and informal forms of accountability intersect and intertwine in contexts where there is an imbalance of power.

\section{R EF E R E N C E S}

Ackerman, J. 2004. "Co-governance for accountability: Beyond "exit" and "voice"'". World Development 32 (3): 447-463.

Blair, H. 2000. "Participation and accountability at the periphery: Democratic local governance in six countries." World Development 28(1):21-39.

Borren, S. 2000. "Development agencies: global or solo players?" Development in Practice 10 (3 \& 4): 408-419.

Cavill, S. and M. Sohail. 2007. "Increasing strategic accountability: a framework for international NGOs." Development in Practice 17:231-248. 
Cliffe, S.,S. Guggenheim, and M. Kostner. 2003. "Community-driven reconstruction as an instrument in war-to-peace transitions." Social Development papers. Conflict prevention and reconstruction series 7 Washington, DC: World Bank.

De Vita, C., C. Fleming, and E.C. Twombly. 2001. "Building non-profit capacity: A framework for addressing the problem", in C. De Vita and C. Fleming (ed.), Building Capacity in Nonprofit Organizations Washington: The Urban Institute, pp. 5-30.

Eade, D. 2007. Capacity building: who builds whose capacity? Development in Practice 17 (45): 630-639.

Fearon, J.D., M. Humphreys, and J.M. Weinstein. 2009. "Can development aid contribute to social cohesion after Civil War? Evidence from a field experiment in post-conflict Liberia." American Economic Review: Papers \& Proceedings 99 (2): 287-291.

International Rescue Committee (IRC) and Care International. 2009. Les protocoles de TUUNGANE en République Démocratique du Congo." Bukavu: IRC: 1-72.

Hilhorst, D. 2003. The Real World of NGOs: Discourses, Diversity and Development. London: Zed Books.

Hilhorst D., I. Christoplos and G. van der Haar. 2010. "Reconstruction from below: a new magic bullet or shooting from the hip?" Third World Quarterly 31 (7): 1107-1124.

Humphreys, M. (2008) Community-driven reconstruction in the Democratic Republic of Congo, Baseline Report. New York (NY): Columbia University: 1-49.

Humphreys, M., R.S. De la Sierra and P. Van der Windt. 2012. Social and Economic Impacts of Tuungane: Final Report on the Effects of a Community Driven Reconstruction Programme in Eastern Democratic Republic of Congo. New York (NY): Columbia University. 
Kyamusugulwa, P.M. 2013. "Local ownership in community-driven reconstruction in the Democratic Republic of Congo." Community development 44 (3): 364-385.

Kyamusugulwa, P.M., D. Hilhorst and G. Van der Haar. 2014. "Capacity builders for governance: community-driven reconstruction in the eastern Democratic Republic of Congo." Development in Practice 24 (7): 812-826.

Kyamusugulwa, P.M. and D. Hilhorst. 2015. "Power holders and social dynamics of participatory development and reconstruction: Cases from the Democratic Republic of Congo." World Development 70: 249-259.

Malena, C., R. Forster and J. Singh. 2004 "Social accountability: an introduction to the concept and emerging practice." Social Development Papers: Participation and Civic Engagement 76.

Maynard, K. and Jodi, N. (2007) The role of culture, Islam and tradition in community-driven reconstruction. A study on International Rescue Committee's approach to Afghanistan's National Solidarity Programme." New York: International Rescue Committee:1-20.

McLean, K. R. Serrano, L. Helling and J. Orac. 2005. Exploring Partnerships between Communities and Local Governments in Community Driven Development: A Framework. Washington, D.C. Environmentally and socially sustainable development network, the World Bank, pp.1-91.

Pellini, A. and D. Ayres. 2007. "Community participation in local governance in Cambodia: Learning from the village networks approach." Development in Practice 17 (3): 404-409.

Reyntjens, F. 2007. "Briefing: Democratic Republic of Congo: Political transition and beyond." African Affairs 106/423: 307-317.

Rubenstein, J. 2007. "Accountability in an unequal world." The Journal of Politics 69(3): 616632. 
Trefon, T. 2011. Congo Masquerade: The political culture of aid inefficiency and reform failure. London/New York: Zed Books. 